\title{
Surgical Retreatment of an Invaginated Maxillary Central Incisor Following Overfilled Endodontic Treatment: A Case Report
}

\author{
Hakan Ozbas ${ }^{a}$ \\ Rustem Kemal Subay ${ }^{b}$ \\ Melike Orduluc
}

\section{ABSTRACT}

This case report presents the periapical surgical retreatment of an Oehlers Class III invaginated maxillary central incisor with extruded root canal filling into the periapical lesion. After local anesthesia, a full-thickness mucoperiosteal flap was reflected, and the granulomatous tissue and extruded gutta-percha points were curetted carefully. A deep and wide root-end cavity was prepared and filled with mineral trioxide aggregate (MTA). At 6 months and 2 years after the treatment, the tooth exhibited no clinical symptoms, and the radiograph performed during the 2-year follow-up showed a complete periapical healing around the root end. The present report indicates that MTA retrofilling can be used successfully in the surgical retreatment of dens invaginatus type III cases in which the invagination exits apically. (Eur J Dent 2010;4:324-328)

Key words: Central incisor; Dens invaginatus; Overfilling; Periradicular surgery.

a DMD, PhD, Associate Professor, Department of Endodontics, School of Dentistry, Istanbul University, Istanbul, Turkey.

b DMD, PhD, Professor, Department of Endodontics, School of Dentistry, Istanbul University, Istanbul, Turkey.

c DMD, PhD, Assistant Professor, Department of Oral and Maxillofacial Surgery, School of Dentistry, Istanbul University, Istanbul, Turkey.

- Corresponding author: Rustem Kemal Subay Department of Endodontics, School of Dentistry, Istanbul University, 34093,Capa, Fatih, Istanbul, Turkey

Fax : +902125250075

E-mail : ctsubaydayahoo.com

\section{INTRODUCTION}

Dens invaginatus (dens in dente) is a developmental anomaly that develops as a result of an invagination in the surface of a tooth crown before biological mineralization takes place. ${ }^{1}$ In a recent study, the tooth prevalence was found to be $0.65 \%$, and the anomaly was present in $2.95 \%$ of people. ${ }^{2}$ In most of the reported cases the lesion is situated unilaterally in maxillary lateral incisors, but mandibular teeth and bilateral cases have also been reported. ${ }^{2,3}$ This anomaly has also been observed in central incisors, canines, bicuspids, and molars. The cause of the anomaly has been related to 
the infolding of the dental papilla during development, allowing the invagination of the inner dental epithelium. The causes of these lesions include external trauma, infection, focal retardation, or focal stimulation of the tooth bud. ${ }^{1-3}$

The invagination has been classified into three types by Oehler. ${ }^{4}$ In the type I case, the enamel invagination is confined in the crown as a blind sac. In the type II case, the enamel-lined invagination invades the root but remains confined within it as a blind sac, and it may communicate with the dental pulp. There are two variations of the type III case: the invagination extends from the crown to the apex forming a second foramen in the apical area, or the invagination forms a second foramen somewhere in the periodontal ligament. The enamel may line the type III invaginations completely, and, in some circumstances, the cementum may cover the invagination apically.

The affected teeth may show unusual crown morphology, such as peg, conic, barrel, or a greater crown size. Clinically, the thin enamel-dentin lining of the invagination usually cannot prevent the entry of bacteria to the pulp space, resulting in pulp necrosis and periapical inflammation. Diagnosis of pulp vitality is important in type III cases. When there is no communication between the invagination and the pulp tissue, the tooth may give a positive response despite the presence of a periapical lesion. ${ }^{5}$ The anomaly may also lead the early pulp necrosis and cause incomplete root development with an open apex. Cases of invaginations associated with talon cusp or in supernumerary teeth have also been reported. 6,7

The endodontic treatment of the anomaly is complicated and varies depending on the invagination types. Type I cases can be treated with preventive sealing, filling of the invagination, or root canal therapy. Type II cases can be treated with root canal therapy, which may involve the removal of the anomalous tissue from the pulp space. For treatment-resistant type II cases, the tooth can be treated in association with periapical surgery and retrofilling. Type III cases in which the invagination ends at the apical foramen can be treated like type II cases. For type III cases in which the invagination opens somewhere in the periodontal ligament, both the necrotic pulp canal and the invagination can be obturated and, in some cases, periapical surgery can be done. In certain cases, the vitality of pulp tissue can be maintained while the invagination is obturated, and sometimes surgery can be done to the periapex of invagination. Intentional replantation can be attempted as a last resort when conventional and surgical treatments are ineffective in resolving the periapical inflammation. ${ }^{3,5-7}$

\section{CASE REPORT}

A 14-yr-old female with no general health problems was referred by her dentist for the treatment of the right maxillary central incisor. The patient reported that the right upper incisor was treated with root canal therapy four months previously. The patient complained of painful swelling on the mucosa over the right upper anterior teeth. Clinically, the tooth was hypersensitive to percussion and palpation. There was a large composite filling on the lingual surface.

Radiographic examination revealed that the right upper central incisor was an invaginated tooth with a large radiolucent lesion (Figure 1). The root canal treatment was insufficient to remediate the condition, and there were extruded gutta-percha points in the lesion.

The patient and her parents stated that they wanted extraction of the tooth and the placement of a single intraosseous implant. The patient was informed that periapical surgery can be performed successfully in this case and accepted periapical surgical treatment.

After local anesthesia, a full-thickness mucoperiosteal flap was reflected, and the granulomatous tissue and extruded gutta-percha points were carefully curetted. The apex of the tooth was resected with a cylindrical bur on a rotary handpiece. A deep and wide root-end cavity was prepared using a round bur. Care was given to preserve the dentinal walls surrounding the anomaly. The retrograde cavity was filled with mineral trioxide aggregate (MTA-Pro Root, Dentsply, Tulsa Dental Companyl. A radiograph was taken to check the quality of the obturation.

The flap was repositioned and sutured. Postoperative medication included an antibiotic, a nonsteroidal anti-inflammatory drug, and a mouth. The sutures were removed after 5 days.

The patient returned for clinical and radiographic examinations 6 months and 2 years after the treatment. The radiograph examination 
performed during the 6-month follow-up showed incomplete bone healing, although there were no clinical symptoms. At the 2-year follow-up, the radiograph examination showed that the tooth exhibited no clinical symptoms, and there was complete periapical healing around the root end. The periapical healing of the case was assessed

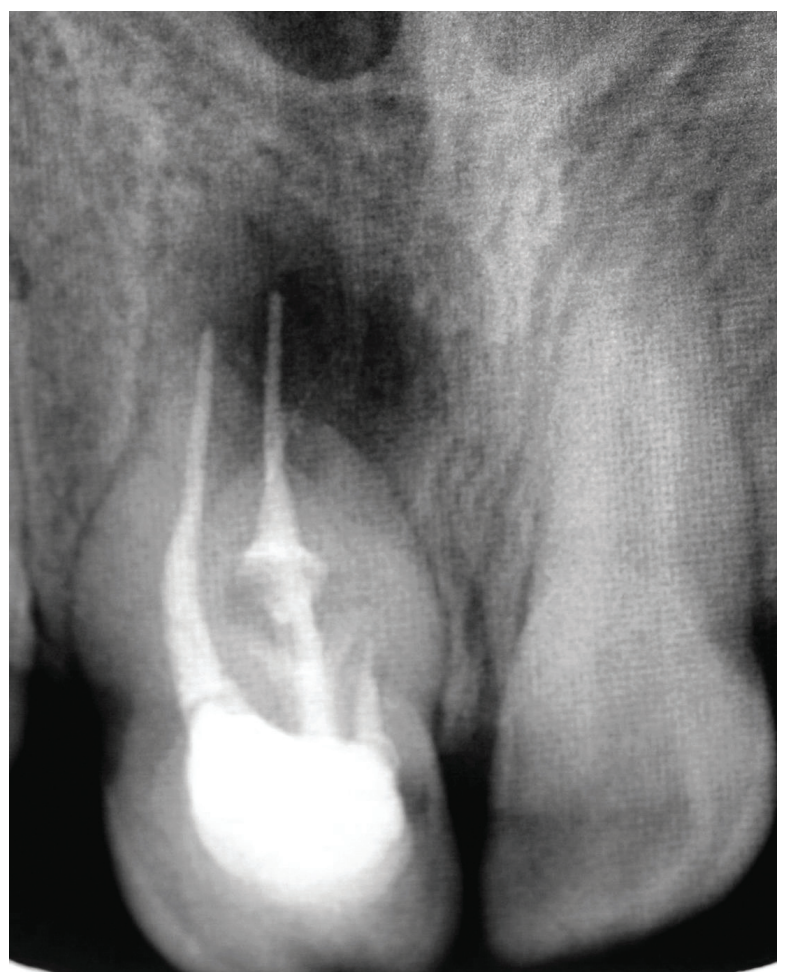

Figure 1. Radiograph of right upper central incisor showing a radiolucent lesion and gutta-percha overfilling.

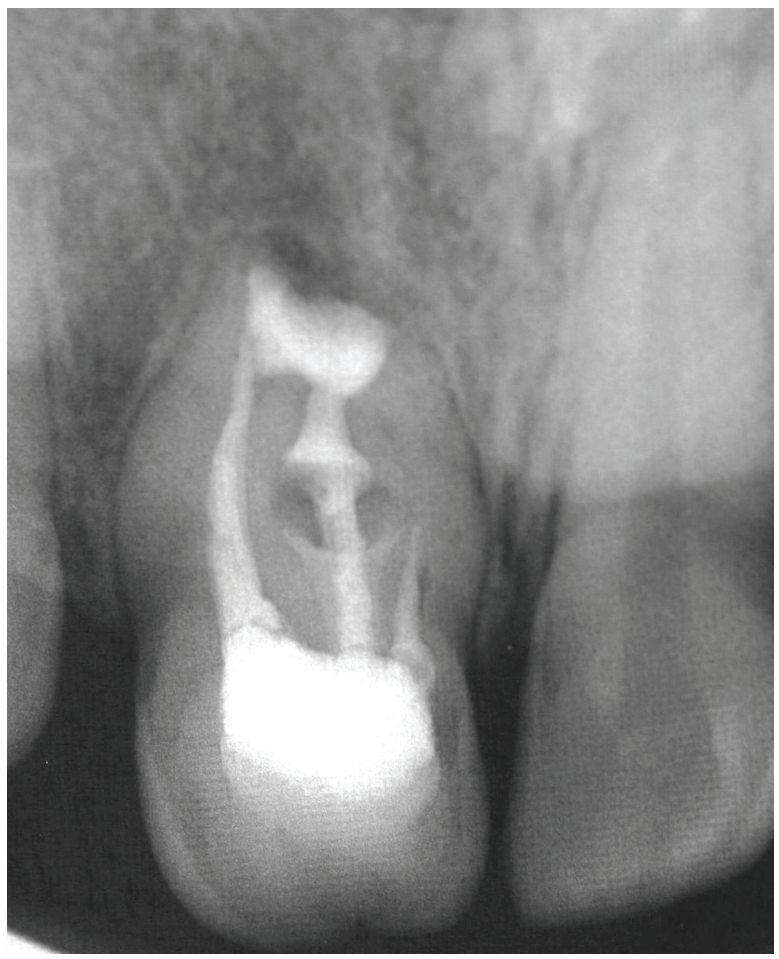

Figure 3. Radiographic control after 6 months. Note incomplete periapical healing around the root end. according to the criteria used by Rud et al. ${ }^{8}$

\section{DISCUSSION}

Non-surgical endodontic treatment in teeth with dens invaginatus type II and III is considered as the first treatment alternative, but endodontic treatment of type II and III cases (the invagination

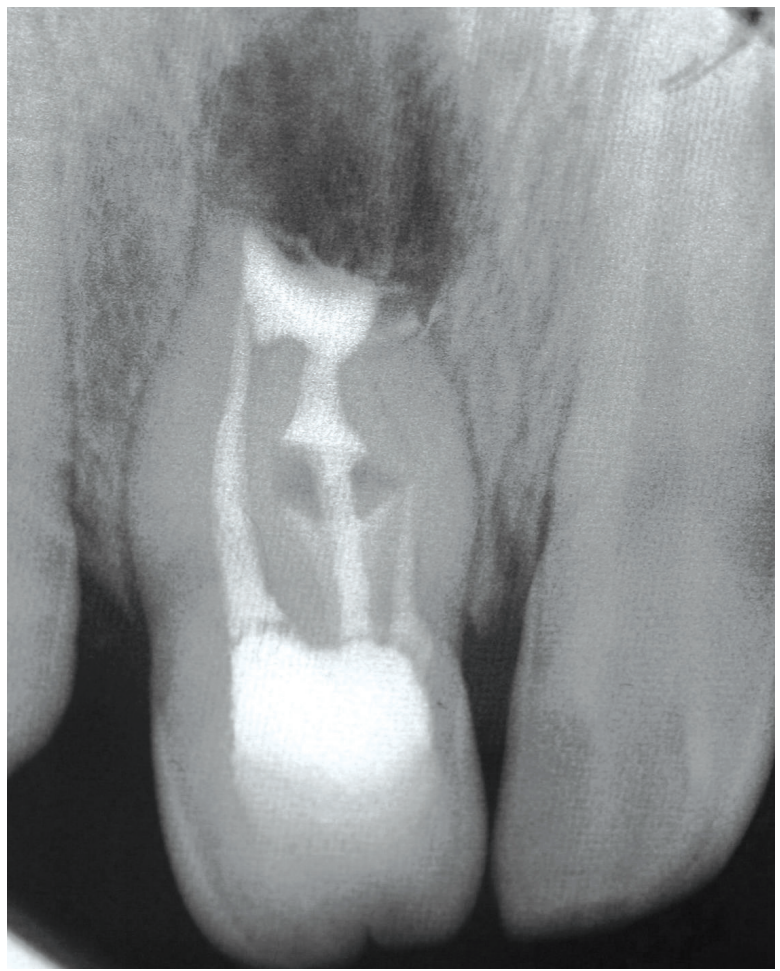

Figure 2. Postoperative control radiograph after surgery.

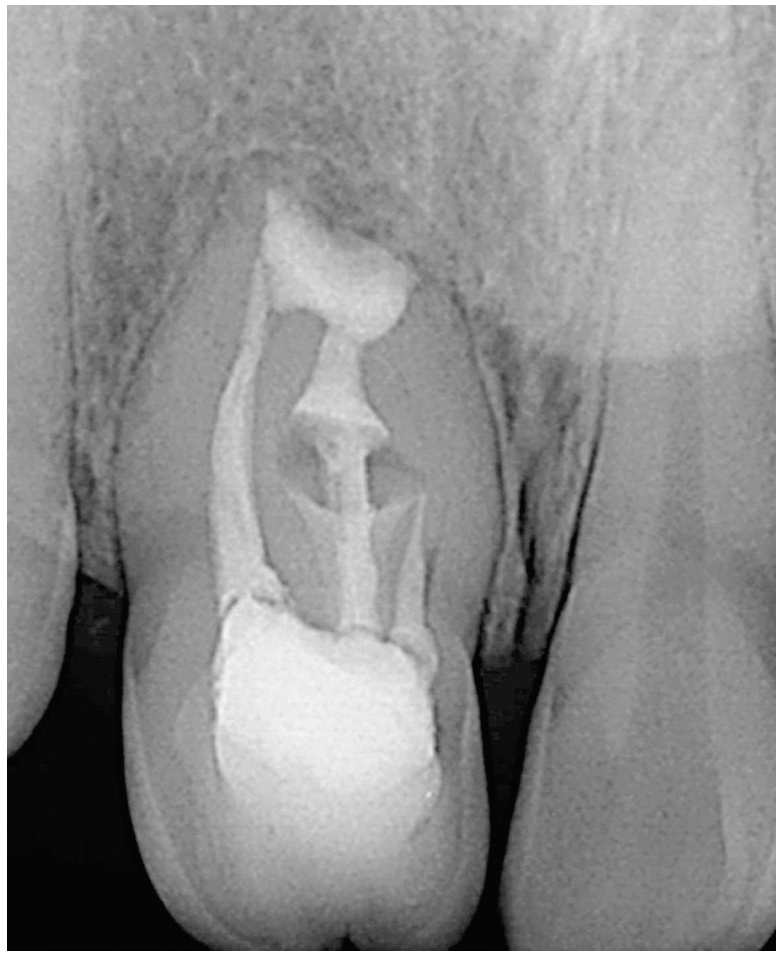

Figure 4. 2-year control radiograph. Complete periapical healing can be seen. 
exits apically) can become complicated because of the canal irregularities between the main canal, and the invagination may prevent the disinfection with calcium hydroxide and eventual success of the root canal treatment. ${ }^{3-7}$ Type II and III cases that were treated with removal of anomalous hard tissue from the canal using the ultrasonics or the larger files have been shown to result in success of the conventional endodontic treatment. ${ }^{9-12}$ It is possible, however, that the removal of invaginatus from the canal may not be performed properly and that a strip perforation may occur in some cases. Furthermore, the elimination of the invagination from the root canal may increase the risk of fracture in the thin root walls. In these cases, root strengthening or reinforcement should be attempted to prevent a severe crown and root fracture, which may occur during or after the treatment. ${ }^{9}$

Surgical treatment of dens invaginatus type II and III cases (the invagination exits apically) is generally considered as the second treatment option when the conventional endodontic management is unsuccessful or in teeth that cannot be treated with conventional treatment due to anatomical or prosthetic reasons. ${ }^{13-16}$

The present case was diagnosed as an Oehlers class III with an invagination that extended all the way from the crown to the apical foramen. There was insufficient root canal treatment in the tooth, with extruded gutta-percha points into the periapical lesion. In this case, endodontic retreatment could not be attempted because the patient did not want to undergo long retreatment procedures. Furthermore, surgical retreatment of this anomalous tooth, which had already experienced an unsuccessful treatment, was also considered to be the convenient endodontic treatment modality in association with MTA retrofilling. ${ }^{6}$

Since the disinfection of the root canal system was not performed, the long-term success of the case depended entirely upon the performance of MTA retrofilling. MTA was used as a retrofilling material mainly because of its superior sealing ability compared to other retrofilling materials as well as its higher biocompability and stimulation effect in the regeneration of periapical tissues. ${ }^{17,18}$

Follow-up at 6 months and 2 years showed progressive and then complete healing. The tooth showed incomplete periapical healing at the 6-month follow-up, but there was complete radiological periapical healing with complete reconstitution of bone and regeneration of periodontal ligament at 2-year follow-up. Clinically, there was no sinus track and no tenderness to palpation or percussion between the 6-month to 2-year follow-up. The present report describes the surgical retreatment of dens invaginatus type III cases in which the invagination exits apically. MTA retrofilling can be used successfully in these cases.

\section{REFERENCES}

1. Shafer WG, Hine MK, Levy BM. A textbook of pathology. $4^{\text {th }}$ ed. Philadelphia: WB Saunders, 1983:41-42.

2. Hamasha AA, Alomari QD. Prevalance of dens invaginatus in Jordanian adults. Int Endod J 2004;37:307-310.

3. Hülsmann M. Dens invaginatus: aetiology, classification, prevalence, diagnosis and treatment considerations. Int Endod J 1997;30:79-90.

4. Oehlers FAC. DI (dilated composite odontome) I. Variations of the invagination process and associated anterior crown forms. Oral Surg Oral Med Oral Pathol 1957;10:1204-1218.

5. Gonçalves A, Gonçalves M, Oliveria DP, Gonçalves N. Dens invaginatus type III: report of a case and 10-year radiographic follow-up. Int Endod J 2002;35:873-879.

6. Sübay RK, Kayatas M. Dens invaginatus in an immature maxillary lateral incisor: a case report of complex endodontic treatment. Oral Surg Oral Med Oral Pathol Oral Radiol Endod 2006;102:37-41.

7. Fregnani ER, Spinola LF, Sonego JRO, Bueno CES, De Martin AS. Complex endodontic treatment of an immature type III dens invaginatus. A case report. Int Endod J 2008;41:913919.

8. Rud J, Andreasen JO, Moller Jensen JE. Radiographic criteria for the assessment of healing after endodontic surgery. Int J Oral Surg 1972;1:195-214.

9. Jaramillo A, Fernandez R, Villa P. Endodontic treatment of dens invaginatus. A 5-year follow-up. Oral Surg Oral Med Oral Pathol Oral Radiol Endod 2006;101:E15-E21.

10. Girsch WJ, McClammy TV. Microscopic removal of DI. J Endod 2002;28:336-339.

11. Er K, Kuștarcı A, Özan Ü, Tașdemir T. Nonsurgical endodontic treatment of dens invaginatus in a mandibular premolar with large periradicular lesion:a case report. $J$ Endod 2007;33:322-324.

12. Kristoffersen $\emptyset, \mathrm{Nag} \mathrm{OH}$, Fristad I. Dens invagnatus and treatment options based on a classification system. Report of a type II invagination. Int Endod J 2008;41:702-709. 
13. Sauveur G, Roth F, Sobel M, Boucher Y. Surgical treatment of a periradicular lesion on an invaginated maxillary lateral incisor (dens in dente). Int Endod J 1997;30:145-149.

14. Beltes P. Endodontic treatment in three cases of dens invaginatus. $J$ Endod 1997;23:399-402.

15. Tomruk CÖ,Tanalp J, Yurdagüven H, Ersev H. Endodontic and surgical management of a maxillary lateral incisor with type III dens invaginatus: a 12-month follow-up. Oral Surg Oral Med Oral Pathol Oral Oral Radiol Endod 2008;106:8487.

16. Kusgoz A, Yıldırım T, Kayıpmaz S, Sarıcaoglu S. Nonsurgical endodontic treatment of type III dens invaginatus in maxillary canine. An 18-month follow-up. Oral Surg Oral Med Oral Pathol Oral Radiol Endod 2009;107:103-106.

17. Torabinejad M, Hong CU, Lee SJ, Monsef M, Pitt Ford TR. Investigation of mineral trioxide aggregate for root end filling in dogs. $J$ Endod 1995;21:603-608.

18. Saidon J, He J, Zhu Q, Safavi K, Spangberg LS. Cell and tissue reactions to mineral trioxide aggregate and Portland cement. Oral Surg Oral Med Oral Pathol Oral Radiol Endod 2003;95:483-489. 